\title{
BMJ Open Working conditions and compensated sickness absence among nurses and care assistants in Sweden during two decades: a cross-sectional biennial survey study
}

Staffan Marklund, ${ }^{1}$ Klas Gustafsson, ${ }^{1}$ Gunnar Aronsson, ${ }^{2}$ Constanze Leineweber, ${ }^{3}$ Magnus Helgesson (D) ${ }^{1}$

To cite: Marklund $S$, Gustafsson K, Aronsson G, et al. Working conditions and compensated sickness absence among nurses and care assistants in Sweden during two decades: a cross-sectional biennial survey study. BMJ Open 2019;9:e030096. doi:10.1136/ bmjopen-2019-030096

- Prepublication history for this paper is available online. To view these files, please visit the journal online (http://dx.doi. org/10.1136/bmjopen-2019030096).

Received 26 February 2019 Revised 02 October 2019 Accepted 03 October 2019

Check for updates

(C) Author(s) (or their employer(s)) 2019. Re-use permitted under CC BY-NC. No commercial re-use. See rights and permissions. Published by BMJ.

${ }^{1}$ Division of Insurance Medicine, Department of Clinical Neuroscience, Karolinska Institutet, SE-171 77 Stockholm, Sweden, Karolinska Institutet, Stockholm, Sweden

2Department of Psychology, Stockholm University, Stockholm, Sweden

${ }^{3}$ Stress Research Institute, Stockholm University, Stockholm, Sweden

Correspondence to Dr Magnus Helgesson; magnus.helgesson@ki.se

\section{ABSTRACT}

Objectives The aims of the study were to trace the patterns of work environment factors and compensated sickness absence (SA) among nurses and care assistants compared with other occupations and to compare SA among exposed and non-exposed nurses and care assistants.

Design A cross-sectional survey on work environment factors based on the biennial Swedish Work Environment Surveys 1991-2013, linked to longitudinal register data on SA 1993-2014.

Participants The study included 98249 individuals, stratified into nurses and care assistants $(n=16179)$ and a reference population including all other occupations $(n=82070)$.

Outcome measure Annual days of compensated SA (>14 days) 3 years after exposure years.

Results Nurses and care assistants had higher SA in 1993-2014 compared with all other occupations, and differences in background factors only partly explained this relationship. For both groups, exposure to physical work factors remained steady, but the number of exposed were $10 \%-30 \%$ higher among nurses and care assistants. Those exposed to heavy physical work and strenuous working postures had in most years significantly higher SA when compared with nonexposed (rate ratio range: 1.4-1.9). Exposure to high job demands increased 10\%-25\% in 1991-1999 among nurses and care assistants but became more stable in 2001-2013 and high proportions of high job demands coincided with the increase in SA in 1995-1999. Nurses and care assistants exposed to high job demands had for most years significantly higher SA than non-exposed (rate ratio range: 1.5-2.1). Low job control and low support from supervisors elevated SA significantly only for a few years.

Conclusions Exposure to negative work factors among nurses and care assistants was weakly associated with variations in SA, but may be related to their higher level of SA when compared with other occupations. Improved physical and psychosocial working conditions may reduce the elevated SA level in these occupations.
Strengths and limitations of this study

The study was based on a large data collection

- Work environment indicators have been measured independently of compensated sickness absence.

- The use of repeated aggregate data does not allow for causal interpretations.

- The study cannot assess possible differences between employees in healthcare and other occupations regarding private life demands.

\section{INTRODUCTION}

Since the end of the 1990s, sickness absence has increased rapidly among nurses and care assistants in Sweden. ${ }^{12}$ Also, increases in the length of sickness absence periods and in the cases of sickness absence due to psychiatric diagnoses have been seen in these occupations. ${ }^{3}$ Moreover, sickness absence levels in Sweden have varied considerably over the years. When the current legislation was introduced in 1955, the average number of annual days of sickness absence was

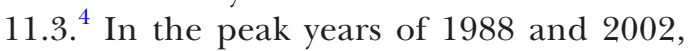
the average was 25.3 and 20.9 days of sickness absence, respectively. Growing differences between women and men have also emerged. As health and social care is a large employment sector and strongly female dominated, changes of working conditions in occupations within this sector affect female sickness absence in general. A more detailed description of the trends occurring in sickness absence and exposures to working conditions among health and social care employees may therefore help improve our understanding of employment conditions in this sector and contribute to our understanding of the potential reasons for 
the increased differences in sickness absence between women and men.

\section{Background}

Previous research on work-related risk factors for sickness absence

There are many different reasons behind the occurrence of sickness absence. A literature review listed a range of individual factors such as age, health status, private life circumstances, consumption of alcohol and smoking. ${ }^{5}$ Reviews and individual studies have shown that various aspects of working conditions also have an impact. ${ }^{5-8}$ Physical and psychosocial work factors have dominated previous research on sickness absence, but the number of studies is more limited on the relationship between these work environment factors and sickness absence among healthcare staff. However, a couple of recent studies have shown that sickness absence management service reduced the excess sickness absence duration among healthcare workers. ${ }^{910}$

\section{Physical work environment factors}

Review studies have found associations between musculoskeletal pain and exposure to both heavy physical work and strenuous working conditions. These studies have also confirmed that musculoskeletal pain is a commonly reported reason for sickness absence among employees in various occupations. ${ }^{11}$ Although studies on these factors generally do not take into account the aspect of work settings, heavy physical work and strenuous working postures may take different expressions in different occupations. In industrial settings and trades, heavy work and strenuous work positions are related to the handling of objects and machinery. In healthcare, heavy physical work and strenuous postures concern the handling of patients or clients rather than things, which may affect the effects of each of these work exposures.

Studies on the negative effects of physical work in healthcare occupations are rare and have produced differing results. A Norwegian study of nurse's aides found no association between heavy physical work and sickness absence, ${ }^{12}$ while a Danish study of healthcare staff did find such an association. ${ }^{13} 14$ A Danish study of employees in old age care also reported associations between heavy physical work and future sickness absence. ${ }^{15} \mathrm{~A}$ study from Finland, which included women in healthcare and care work, also showed associations between heavy physical work and sickness absence. ${ }^{8}$ In addition to heavy lifting and difficult working positions, research has shown that exposure to detergents or human secretions, which are common among healthcare staff, increased the risk for hand eczema and work absence. ${ }^{16}$

\section{Psychosocial work environment factors}

A couple of Swedish studies have found an increase over the last decade in sickness absence due to psychiatric diagnoses, arguing that it may be linked to a simultaneous increase in negative psychosocial exposures in many occupations. ${ }^{3}{ }^{17}$ In these reviews, as well as in individual studies, high job demands, low job control and lack of social support at work have been identified as the three most frequent psychosocial aspects found to be associated with health problems and sickness absence in various occupations. ${ }^{18-22}$

Studies of healthcare employees in different countries have also shown that psychosocial factors affect the risk of sickness absence, although the measures of psychosocial load have varied. ${ }^{12} 2123-29$ Occupations within the healthcare sector can be expected to have especially demanding psychosocial working conditions, as they involve dealing with sick and old people in vulnerable and acute situations.

\section{Aims}

The main objective of this study was to describe the trends in exposure to work environment factors (measured every second year between 1991 and 2013) and in sickness absence (measured between 1993 and 2014) among nurses and care assistants in Sweden and to compare their exposure and compensated sickness absence with that of other occupations.

- The first aim was to describe how the number of compensated sickness absence days ( $>14$ days) and exposures to physical and psychosocial work environment factors have changed over time among nurses and care assistants compared with employees in other occupations.

- The second aim was to assess changes over time in the number of compensated sickness absence days, while adjusting for differences in age and sex composition among nurses and care assistants and other occupations under study.

- The third aim was to compare the number of compensated sickness absence days among nurses and care assistants who were exposed to negative physical and psychosocial work environment factors with that of nurses and care assistants who were not exposed to these factors.

\section{METHODS}

\section{Study population}

This study was based on 98249 working men and women who participated in any of the biennial Swedish Work Environment Survey (SWES) between 1991 and 2013. The following three categories are included in the category nurses and care assistants: nursing and midwifery professionals (Swedish Standard for Occupational Classification year 1996 (SSYK96): number 223; $\mathrm{n}=1210$ ), nursing associate professionals (SSYK96: 323; $\mathrm{n}=1843$ ) and employees in personal social care (SSYK96: 513: $\mathrm{n}=13126$ ). Nursing and midwifery professionals include specialised and non-specialised nurses working in hospitals and other healthcare organisations. Nursing associate professionals and those employed in personal care include assistant nurses, hospital ward assistants, home-based personal care workers and assistants in childcare. A comparison 
group was also used, consisting of employees from all of the other occupations in the database. In total, data from 16179 nurses and care assistants and 82070 employees from other occupations were utilised in this study.

\section{Data collection}

Data for this study were mainly derived from the SWES that covers a broad range of work conditions. ${ }^{30}$ It has been conducted every second year since 1989 and is based on random samples of the Swedish employed population aged 16-64. The survey starts with a telephone interview which is followed up by a postal survey. The annual response rates varied between $66 \%$ and $89 \%$ during the period between 1989 and 2013, and the participants were consecutively added to the cohort. As we only have data on annual sickness absence days, the follow-up period, in which participants' sickness absence was tracked, started the year after the interview and spanned the following three calendar years. As the interviews took place between January and March each year, the period between answering the survey and the measurement of sickness absence varied between 9 months and 12 months. The follow-up period for each participant ended on December 31 of the third year after the interview or the year they were granted disability pension, emigrated or died, whichever came first. Thus, for those who answered the survey in 1999, we tracked their compensated sickness absence by accounting for all of their annual sickness absence periods between 1 January 2000 and 31 December 2002 which lasted longer than 14 days.

Information on background factors and annual days with compensated sickness absence was attained from the Longitudinal Database for Health Insurance and Labour Market Studies (LISA) (1993-2014) at Statistics Sweden.

The choice of variables in this study was governed by two principles. One was to use work environment variables that many previous studies had found to be related to sickness absence. Another was to use variables that had been included in the surveys for a long time period. Unfortunately, this meant having to exclude some potentially interesting work-related factors which had only been examined in a few data collections of SWES. In some cases, survey questions had been changed at some point and were therefore excluded in this study. Data on heavy physical work and strenuous working postures were missing in 2003. Moreover, information about shift work and working hours would have been valuable as potential confounders in this study, but the survey did not have information on these factors.

\section{Measurement of sickness absence}

The numbers of annually compensated sickness absence days (>14 days) for each of the 3 years following the year of participating in the work environment survey were added together to serve as the outcome variable. The regulations for public sickness absence compensation in Sweden changed during the study period, but for most of the years, the first day of a sick-leave period was not compensated and days 2-14 were covered by the employer. Register data are not available for sickleave periods of 14 days or less. In this study, only days compensated by the Swedish social insurance scheme were included. To qualify as a case of compensated sickness absence in the public system, the period of sickness absence must have a duration of more than 14 days. A medical certificate corroborating the loss of work ability is required after 7 days of absence, and thus all sickness absence covered in this study was medically certified by a physician.

Compensated sickness absence was calculated as the annual average number of days over the 3 years following the year of the interview. Net days were used, which resulted in part-time sickness absence being included as a fraction, that is, 2 days of half-time sickness absence constitutes one net day. It should be noted that the calculation of the average number of compensated sickness absence days for those interviewed in 1991 was based on only 2 years, 1993 and 1994, since the data for 1992 were missing. For those interviewed in 2013, only 1 year, 2014, was used in the calculation due to a lack of data for later years.

\section{Work environment indicators}

The first three variables below concern physical work environment factors, while the last three concern psychosocial work conditions.

The data on physical and psychosocial work environment exposures were obtained from SWES, 1991-2013. ${ }^{30}$ Similar to other studies, and in order to balance between statistical power and exposure contrasts, the response options were dichotomised closest to the upper quartile to indicate adverse conditions. ${ }^{31}$

The following item was used as an indicator of heavy physical work:

- Does your job mean that your work is purely physical, that is, do you put in more physical effort than you do when you walk, stand, and move in the usual way?'

Those who answered 'Yes' by selecting 'every day', 'a couple days per week', '1 day per week' or 'a couple days per month' were categorised as exposed.

The following item was used as an indicator of strenuous working postures:

- 'Do you work in a twisted position?'

Those who answered 'Yes' by selecting 'nearly all the time', 'about $3 / 4$ of the time', 'half the time', 'about $1 / 4$ of the time' or 'about $1 / 10$ of the time' were categorised as exposed.

One item on exposure to chemical substances was used. This concerned working with detergents or disinfectants:

- 'Are you in your work exposed to detergents and/or disinfectants (in contact with the skin)?'

Those who answered 'Yes' by selecting 'nearly all the time', 'about $3 / 4$ of the time', 'half the time', 'about $1 / 4$ of the time' or 'about $1 / 10$ of the time' were categorised as exposed. 
Job demands have been measured using the following statement, where respondents were asked to what degree they agreed or disagreed with the item on a 5-point scale:

- 'I have far too much to do at work'

Those who responded with 'Yes' by selecting 'I agree' or 'partly agree' were considered exposed.

The item for job control was the following statement where the respondent was asked to agree or disagree on a 5-digit scale:

- 'I have too little influence at work'

Responses that included 'Yes, I agree' or 'Yes, I partly agree' were seen as indicating exposure.

Social support from supervisors was captured by the following question:

- Do you have the opportunity to get support and encouragement from supervisors when work feels difficult'

Individuals who answered 'mostly not' or 'never' were considered exposed to poor social support from supervisors.

\section{Background factors}

Sex (men, women), age ( $<31$ years, $31-40$ years, $41-50$ years, $\geq 51$ years), employment sector (public, private) and educational level (elementary school, upper secondary school, university) were used as control variables.

\section{Statistical analyses}

The least square (LS) means were estimated for each interview year with regard to average days of compensated sickness absence for the 3 years following the year of the interview for the period 1993-2014. We also applied weights to the LS means coefficients with regard to age and sex, as well as the interaction between age and sex. This enabled us to calculate the sickness absence days among nurses and care assistants as if the age and sex distributions were the same as in the general population.

Moreover, unadjusted means for the annual number of compensated days of sickness absence (3years following the interview year) were calculated for those exposed and non-exposed to the measures of physical and psychosocial work exposures.

We also calculated the adjusted rate ratios (RRs), with 95\% CI, for average days of compensated sickness absence among those exposed and unexposed for all six physical and psychosocial exposures, controlling for sex, educational level and employment sector.

In all calculations, generalised estimating equations with exchangeable correlations between observations were used, assuming a negative binomial distribution for the response variable (SAS statistical software, procedure: 'Proc Genmod'). All analyses were performed using the SAS statistical software V.9.4.

\section{Ethical considerations}

The Swedish Law on Research Ethics states that the use of register data which have been given without consent and contain sensitive information (eg, regarding health conditions) must get approval from a regional research ethics committee. This applied to our sickness absence data, while participation in the work environment survey was based on informed consent. The approval must be sought for research use of personal information as well where anonymisation has taken place after the data linkage.

\section{RESULTS}

\section{Characteristics of the study population}

The main characteristics of the two groups in the study, nurses and care assistants, on the one hand, and 'other occupations', on the other hand, are shown in table 1 . The most striking difference between the two groups is the distribution of men and women. Among nurses and care assistants, between 1991 and 2013 91.6\% were women, while the proportion of women in other occupations was $44.0 \%$. University level education was more common among nurses and care assistants $(61.1 \%)$ than among other occupations (46.3\%), and the percentage working in the public sector was higher among nurses and care assistants $(83.5 \%)$ than among the other occupations group $(29.1 \%)$. The age distribution and the distribution of other background factors were similar among the groups.

\section{Compensated sickness absence, 1993-2013}

Sickness absence in terms of compensated days has fluctuated over the last two decades in Sweden. As presented in figure 1 , there was a distinct increase in the number of compensated sickness absence days in the general working population as well as among nurses and care assistants in the late 1990s and early 2000s.

As compared with the general working population, the increase in compensated sickness absence was greater among nurses and care assistants during these years. In 1999 the average number of annual compensated sickness absence days was twice as many among nurses and care assistants (30 days) as compared with other occupations (15 days). Also, the unadjusted average number of sickness absence days was higher among nurses and care assistants than among the other occupations group throughout the study period.

However, when age and sex were adjusted for, nurses and care assistants had a lower average number of compensated sickness absence days than other occupations for the first 4 years of the study period, 1991-1995. The increase in sickness absence days in the latter part of the 1990s was more rapid among nurses and care assistants than among other occupations. This remained the case even when sickness absence days were adjusted for differences in sex and age. After 2007, there was again an increasing trend in compensated sickness absence days among nurses and care assistants, while the average for other occupations remained stable (figure 1).

\section{Physical and psychosocial working conditions}

In the years 1991-2013, between $34 \%$ and $39 \%$ of nurses and care assistants, and between $22 \%$ and $27 \%$ of those in 
Table 1 Characteristics of participants in the work environment surveys (SWES), 1991-2013

\begin{tabular}{|c|c|c|c|c|}
\hline & \multicolumn{2}{|c|}{$\begin{array}{l}\text { Nurses and } \\
\text { care assistants }\end{array}$} & \multicolumn{2}{|c|}{$\begin{array}{l}\text { Other } \\
\text { occupations }\end{array}$} \\
\hline & $\mathbf{N}$ & $\%$ & $\mathbf{N}$ & $\%$ \\
\hline \multicolumn{5}{|l|}{ Sex } \\
\hline Men & 1363 & 8.4 & 45925 & 56.0 \\
\hline Women & 14811 & 91.6 & 36095 & 44.0 \\
\hline \multicolumn{5}{|l|}{ Age $^{*}$} \\
\hline$<31$ years & 2352 & 14.5 & 11619 & 14.2 \\
\hline $31-40$ years & 3969 & 24.5 & 19929 & 24.3 \\
\hline $41-50$ years & 4787 & 29.6 & 23682 & 28.9 \\
\hline$>50$ years & 5071 & 31.3 & 26840 & 32.7 \\
\hline \multicolumn{5}{|l|}{ Educational level ${ }^{*}$} \\
\hline Elementary school & 1237 & 7.7 & 15322 & 18.7 \\
\hline Upper secondary school & 5053 & 31.2 & 28788 & 35.1 \\
\hline University & 9879 & 61.1 & 37960 & 46.3 \\
\hline \multicolumn{5}{|l|}{$\begin{array}{l}\text { Children }<18 \text { years living at } \\
\text { home }{ }^{*}\end{array}$} \\
\hline No & 8035 & 54.6 & 42262 & 58.6 \\
\hline Yes & 6683 & 45.4 & 29891 & 41.4 \\
\hline \multicolumn{5}{|l|}{ Civil status* } \\
\hline Unmarried & 6677 & 45.4 & 32590 & 45.2 \\
\hline $\begin{array}{l}\text { Married/registered } \\
\text { partnership }\end{array}$ & 8041 & 54.6 & 39563 & 54.8 \\
\hline \multicolumn{5}{|l|}{ Region of birth* } \\
\hline Sweden & 14838 & 91.7 & 76037 & 92.6 \\
\hline Western countries & 992 & 6.1 & 4987 & 6.1 \\
\hline Non-Western countries & 349 & 2.2 & 1046 & 1.3 \\
\hline \multicolumn{5}{|l|}{ Sickness absence* } \\
\hline No sickness absence & 12244 & 83.2 & 64043 & 88.8 \\
\hline $\begin{array}{l}\text { 1-90 days of sickness } \\
\text { absence }\end{array}$ & 1874 & 12.7 & 6353 & 8.8 \\
\hline $\begin{array}{l}\text { Over } 90 \text { days of sickness } \\
\text { absence }\end{array}$ & 600 & 4.1 & 1751 & 2.4 \\
\hline \multicolumn{5}{|l|}{ Employment sector* } \\
\hline Public & 12267 & 83.6 & 20836 & 29.1 \\
\hline Private & 2411 & 16.4 & 50666 & 70.9 \\
\hline
\end{tabular}

${ }^{*}$ measured during year of interview.

SWES, Swedish Work Environment Survey.

other occupations, reported that they experienced heavy physical work (figure 2). Between $39 \%$ and $45 \%$ of nurses and care assistants were exposed to strenuous working postures, compared with $20 \%-25 \%$ for other occupations. As expected, the proportion of nurses and care assistants who reported being exposed to chemical substances was large, ranging between $50 \%$ and $60 \%$, while the average for other occupations was between $20 \%$ and $24 \%$ and slowly declining in the last few years (figure 2).

The results regarding the three indictors of psychosocial work factors, that is, high demands, low control and

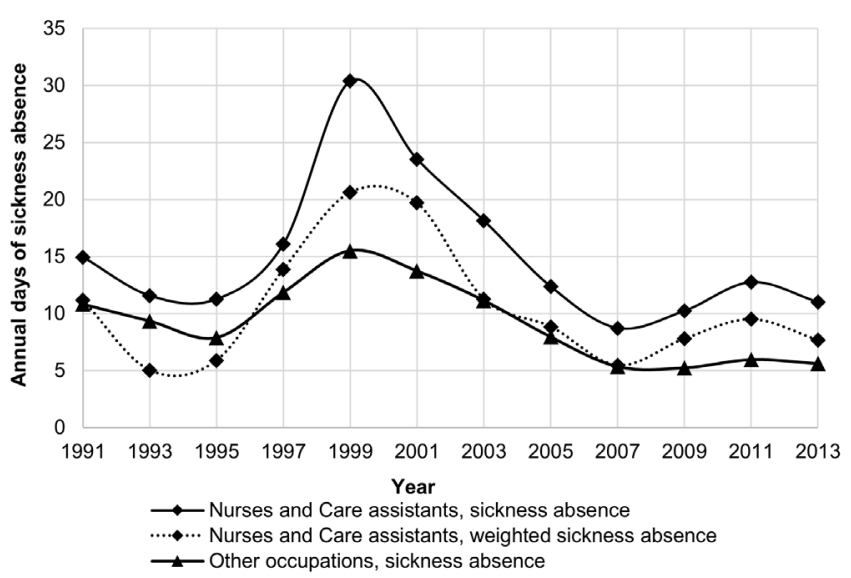

Figure 1 Average number of medically certified sickness absence days, 1991-2013, among nurses and care assistants and all other occupations, including weighted figures for the analysis of nurses and care assistants where the age and sex structure is equivalent in the entire working population.

low social support from supervisors, were different. There were smaller differences between the nurses and care assistants and those in other occupations than were found in regard to physical work factors, although the negative psychosocial indicators changed more over time. For both occupational groups there was a distinct increase in

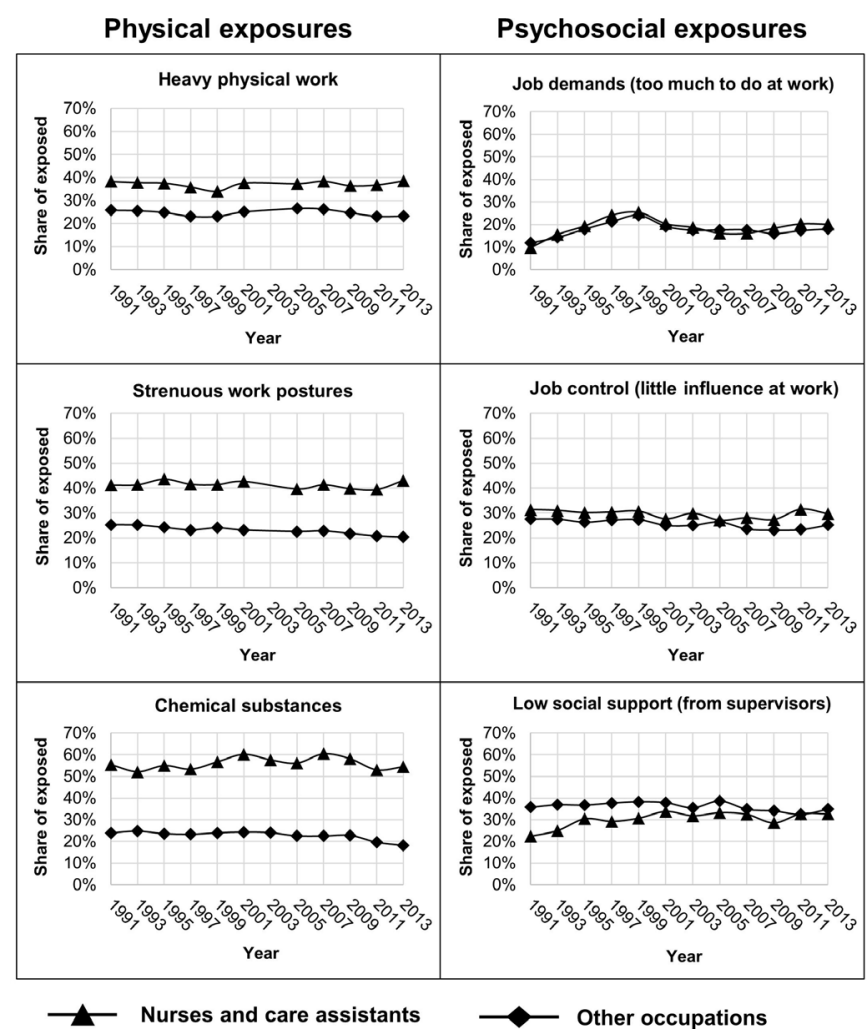

Figure 2 Proportions found to be exposed to the physical and psychosocial risk factors under study among nurses and care assistants and all other occupations, from 1991 to $2013^{*}$. *Values are missing with regard to heavy physical work and strenuous working postures in 2003. 


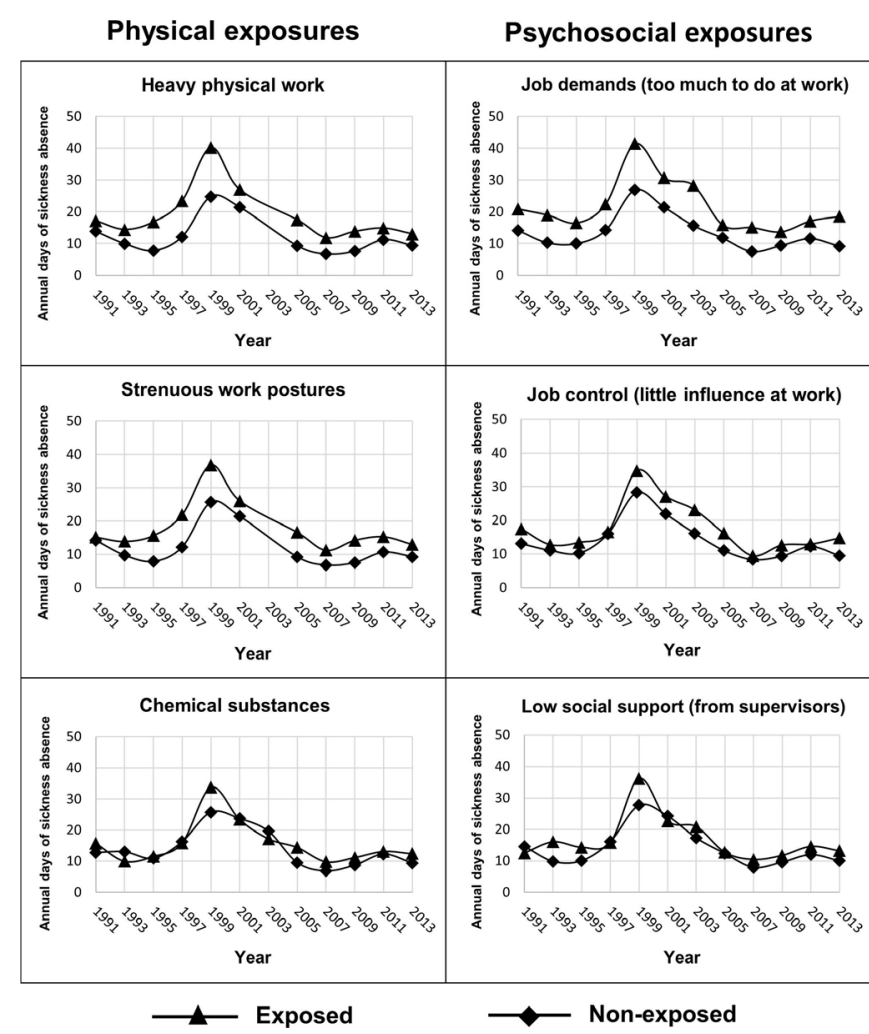

Figure 3 Average annual days of compensated sickness absence during the 3 years after the interview* among nurses and care assistants exposed and not exposed to physical and psychosocial risk factors, 1991-2013. *Data available from 1993.

the 1990s from 10\% reporting high job demands in 1991 to $25 \%$ in 1999 . After that, there was a slow decline over the next 10 years followed by a slow increase in the last few years (figure 2).

The exposure to low job control was stable over time in both occupational groups. Compared with those in the other occupation group, the nurses and care assistants group showed slightly higher proportions of low job control during the years between 1991 and 2013, except for 2005 when both groups had the same level. However, the trend over time for nurses and care assistants was negative, with 22\% in 1991 and 33\% in 2013 reporting poor social support (figure 2).

\section{Compensated sickness absence among those exposed and non-exposed to work environment risks}

Figure 3 presents the average number of annual days of compensated sickness absence for the years under study among exposed and non-exposed nurses and care assistants according to the six work environment indicators.

Among nurses and care assistants that reported a high degree of heavy physical work, the number of annual days of compensated sickness absence was for most years higher than among those in healthcare who did not report this. In 1991, nurses and care assistants exposed to heavy physical work were sickness absent for 22 days as compared with 18 days among the non-exposed. In 1999, those exposed to heavy physical work were sickness absent for
40 compensated days, while the comparable figure is 24 days for the non-exposed. Regarding strenuous working postures, exposed nurses and care assistants showed a generally higher number of sickness absence days than those not exposed, with the difference varying from a few days to 10 days. The differences in compensated sickness absence days in relation to exposure and non-exposure to chemical substances, on the other hand, were generally small and even non-existent for three of the years.

Those exposed to high psychosocial job demands had on average 5-10 additional days of compensated sickness absence than non-exposed. For those exposed to low job control, the average difference when compared with those non-exposed was generally lower and for two of the years there were no differences. Nurses and care assistants reporting low social support from supervisors were also generally sickness absent for between 4 to 8 more days than those who had greater support, but the differences between the two groups were small or non-existent for certain years.

In order to give a more detailed description of the differences in compensated sickness absence days among exposed and non-exposed employees, adjusted RRs for average compensated sickness absence days were estimated (table 2). Values over 1 indicated that those exposed had more sickness absence in the following 3 years compared with those not exposed, while values lower than 1 indicated the opposite.

Exposure to heavy physical work significantly increased the RRs of the number of compensated sickness absence days by between $40 \%$ and 90\% (RR range: 1.4-1.9, 95\% CI 1.0 to 2.8) for most of the years between 1991 and 2013. Similar results were found for strenuous working postures (RR range: $1.4-1.9,95 \%$ CI 1.0 to 2.8 ). In regard to exposure to chemical substances, however, the number of compensated sickness absence days significantly increased for only two of these years (RR range: $1.4,95 \% \mathrm{CI} 1.1$ to 1.9$)$. Among the psychosocial factors, exposure to high demands showed significantly increased numbers of compensated sickness absence days, increases of between $40 \%$ and $110 \%$ for eight of the 12 years (RR range: 1.4-2.1, 95\% CI 1.0 to 3.6). Exposure to low control and low support showed significantly elevated sickness absence for only a few of the years (RR range: 1.3-1.7, $95 \%$ CI 1.0 to 2.1 ). The figures for unadjusted rates were similar (figures not shown). The results show that the differences in annual compensated sickness absence days between those exposed and non-exposed differed over time and according to type of exposure.

\section{DISCUSSION}

Three main findings of this study stand out. First, when compared with those in other occupations, nurses and care assistants in Sweden were found to have a greater average number of compensated sickness absence days, ranging from 3 to 15 more days between 1991 and 2013. For 1999, nurses and care assistants were on average 
Table 2 RRs for sickness absence among exposed and non-exposed nurses and care assistants. adjusted for sex, educational level and employment sector; significant ratios in bold (95\% Cl)

\begin{tabular}{|c|c|c|c|c|c|c|c|}
\hline $\begin{array}{l}\text { Year of } \\
\text { interview }\end{array}$ & $\begin{array}{l}\text { Sickness } \\
\text { absence }\end{array}$ & $\begin{array}{l}\text { Heavy physical } \\
\text { work }\end{array}$ & $\begin{array}{l}\text { Strenuous } \\
\text { working } \\
\text { postures }\end{array}$ & $\begin{array}{l}\text { Chemical } \\
\text { substances }\end{array}$ & High demands & Low control & $\begin{array}{l}\text { Low social } \\
\text { support }\end{array}$ \\
\hline 1991 & 1993-1994 & 1.3 (0.9 to 1.8$)$ & 1.0 (0.7 to 1.5$)$ & 1.2 (0.9 to 1.7$)$ & 1.5 (0.9 to 2.5$)$ & 1.4 (1.0 to 2.0 ) & 0.9 (0.6 to 1.3$)$ \\
\hline 1993 & 1994-1996 & $1.4(1.0$ to 2.0$)$ & $1.4(1.0$ to 2.0$)$ & $0.8(0.5$ to 1.1$)$ & 1.8 (1.2 to 2.7$)$ & $1.1(0.8$ to 1.5$)$ & 1.7 (1.2 to 2.5$)$ \\
\hline 1995 & 1996-1998 & 1.9 (1.3 to 2.8$)$ & $1.8(1.2$ to 2.7$)$ & $1.0(0.7$ to 1.5$)$ & 1.7 (1.0 to 2.6$)$ & $1.4(0.9$ to 2.1$)$ & 1.5 (1.0 to 2.3$)$ \\
\hline 1997 & 1998-2000 & 1.7 (1.2 to 2.4$)$ & 1.6 (1.2 to 2.3$)$ & 0.9 (0.6 to 1.2$)$ & 1.6 (1.1 to 2.2$)$ & $1.1(0.7$ to 1.5$)$ & $1.0(0.7$ to 1.5$)$ \\
\hline 2001 & 2002-2004 & 1.2 (0.9 to 1.5$)$ & $1.2(0.9$ to 1.5$)$ & 1.0 (0.8 to 1.3$)$ & 1.5 (1.1 to 2.0$)$ & 1.3 (1.0 to 1.7$)$ & $1.0(0.7$ to 1.3$)$ \\
\hline 2003 & 2004-2006 & missing data & missing data & 0.9 (0.7 to 1.2$)$ & 1.9 (1.4 to 2.5$)$ & $1.5(1.1$ to 2.0$)$ & $1.2(0.9$ to 1.5$)$ \\
\hline 2005 & 2006-2008 & 1.7 (1.3 to 2.3$)$ & 1.7 (1.3 to 2.2$)$ & $1.4(1.1$ to 1.9$)$ & 1.3 (0.9 to 1.9$)$ & 1.5 (1.1 to 2.1$)$ & 1.1 (0.8 to 1.4$)$ \\
\hline 2007 & 2008-2010 & 1.7 (1.2 to 2.3$)$ & 1.6 (1.2 to 2.3 ) & 1.3 (0.9 to 1.8$)$ & 2.1 (1.4 to 3.1$)$ & 1.1 (0.8 to 1.6$)$ & 1.3 (0.9 to 1.9$)$ \\
\hline
\end{tabular}

$\mathrm{RR}$, rate ratios.

sickness absent for twice as many days (30 days) than those in other occupations (15 days). For 2013, the absolute numbers of days of sickness absence had decreased, but nurses and care assistants still had twice as many sickness absence days (12 days) compared with those in other occupations (6 days). Second, changes in exposure to negative work environment factors over time were not in general found to be related to changes over time in regard to number of sickness absence days among nurses and care assistants. The only exposure factor that may be related to the peak in compensated sickness absence in 1997-2003 was high psychosocial job demands, which increased between 1995 and 1999. Third, the results also show that nurses and care assistants who were exposed to most of the measured negative work environment factors, with the exceptions of exposure to chemical substances and low social support, had significantly higher numbers of compensated sickness absence days as compared with those non-exposed.

The observed trends regarding variations in sickness absence among nurses and care assistants are partly in agreement with results from other Swedish publications. ${ }^{14}$ For example, one publication reported that nursing aides and care assistants had more compensated days of sickness absence, and nurses had initially fewer days of compensated sickness absence, compared with other occupations between 1992 and 2006, before increasing to a slightly higher level than other occupations after 2007. ${ }^{1}$ One study reported that nurses and care assistants in 2015-2016 had more compensated sickness absence days when compared with other occupations. ${ }^{4}$

A number of factors have been suggested to affect the variations in sickness absence over time. A couple of studies have shown an association between changes in compensated days of sickness absence and changes in regulations within the insurance system. ${ }^{32} 33$ One study found that changes in the legal framework, labour force composition and economic cycles all had effects, but could not detect any effects from changes in working conditions. $^{2}$ Contrary to these results, two studies reported that the variations in sickness absence between 1992 and 2008 were related to negative working conditions. $^{3435}$ In line with the present study, these studies found associations between negative psychosocial factors and sickness absence, although they did not specifically examine individuals in health or social care occupations. There are only a few studies available that specifically address trends in sickness absence among nurses and care assistants, and none of them take working conditions into account. ${ }^{9} 1036$ A couple of cross-sectional studies based on aggregate data on healthcare and social care occupations have shown differences in working conditions, both between workplaces and between women and men, but they provide no information about changes over time. ${ }^{1837}$

In contrast to the lack of studies on trends in sickness absence and work environment risks among employees in health and social care, there are a large number of studies on exposure levels and risk of sickness absence among these occupations. The high level of exposure to physically demanding work among health and social care employees found in this study is in accordance with several previous studies on different physical work environment risks that were found to be associated with higher levels of sickness absence. ${ }^{812-16}$

There are a number of reasons why changes over time in sickness absence levels are less attributable to changes in working conditions than are the higher levels of sickness absence among nurses and care assistants when compared with all other occupations. It may have to do with the fact that time trends in regard to sickness absence depend on 
a large number of other time dependent factors such as workforce composition, economic development, changes in legislation and changes in employee or employer attitudes to sickness absence. Another reason for why changes in exposure to work environment risks are often not found to be associated with changes in levels of sickness absence may be that there is a lag in the surfacing of the effects on health and sickness absence from these exposures.

Occupational differences are by definition linked to differences in exposure to work environment factors, and may therefore be more closely linked to differences in sickness absence levels. Thus, it seems reasonable to presume that specific negative work environment factors, either physical or psychosocial, are likely to cause illhealth and subsequent sickness absence.

\section{Strengths and limitations}

The major advantages of this study are that it is based on a large data set and that work environment indicators were measured in a standardised way over a long period of time and independently of sickness absence. The response rate of the surveys was high and the measures of negative exposures that were used have high validity. The measure for compensated sickness absence was based on population registers with high coverage and accuracy. However, the fact that the only data available on sickness absence pertained to those cases that were compensated by the social security system after 2 weeks of absence may be seen as a limitation. Shorter periods of sickness absence would also be of interest, as they may be a way for employees to cope with work-related strain, thus potentially avoiding longer periods of sickness absence.

The study covers periods of high as well as low sickness absence among nurses and care assistants. There have been some minor changes in the legal system for sickness absence during the study period, but research studies have found only weak connections between such changes and sickness absence levels. We believe for these reasons that the findings are relevant today despite the fact that the data do not cover the period after 2013. Futhermore, other studies have shown that working conditions have a role in explaining the higher level of sickness absence among nurses and care assistants even in recent years. ${ }^{1436}$

There are also some other potential methodological issues in the study. The most obvious is that the use of aggregate data does not allow for causal interpretations. Relatedly, the estimated mean values of this study were often characterised by large CI. This indicates that the working environment may be both better and worse for large groups. Even though this issue may not necessarily or considerably affect the description of changes over time, or the differences between the two occupational groups, it limits the strength of any conclusions. More research is therefore needed to explore if other aspects of the working environment or work organisation may affect sickness absence among nurses and care assistants. This may include investigations of the effects of the introduction of new management structures, longer working hours, shift work and increased administrative responsibilities. Furthermore, most employees in nursing and social care are simultaneously exposed to several risks and it is likely that combinations of different physical and psychosocial risks would show stronger associations with sickness absence than separate factors. Therefore, studies that consider interaction effects of multiple work exposures, both physical and psychosocial, are warranted.

\section{CONCLUSIONS}

Nurses and care assistants had more annual days of compensated sickness absence between 1991 and 2013 than those in our all other occupations group. Only weak associations between changes over time in compensated sickness absence and changes in exposure to negative work environment factors were found. The only work environment factor associated with an increase in compensated sickness absence over 1995-2000 was high job demands, which showed an increasing trend over this period.

On the other hand, the higher level of compensated sickness absence among nurses and care assistants was linked to a higher proportion of individuals exposed to some of the detrimental work environment factors. Those exposed were also generally sickness absent for more days than those non-exposed. The study indicates that improved physical and psychosocial working conditions for nurses and care assistants could lower the sickness absence levels in these occupations.

More research is needed in order to fully understand the complexities of variations and prevalences of sickness absence among nurses and care assistants. This could include taking a wider range of work environment changes into account, but also epidemiological studies on individuals may be useful for revealing more detailed information about other types of factors. Moreover, co-exposure to simultaneous work-related risks, such as negative physical and psychosocial work conditions, should be considered in the analyses.

Contributors $\mathrm{MH}, \mathrm{SM}, \mathrm{KG}, \mathrm{CL}$ and GA made substantial contributions to the conception and design of the study. MH did the analyses in collaboration with KG and SM. SM drafted the manuscript and MH, KG, CL, and GA revised the manuscript critically on several occasions. All authors approved the final manuscript.

Funding The study was funded by AFA Insurance, Sweden, grant number 170114 . Competing interests None declared.

Patient consent for publication Not required.

Ethics approval The regional ethical board in Stockholm approved this study (dnr. 2018/223-31/5) and waived the requirement that informed consent from the research subjects should be collected.

Provenance and peer review Not commissioned; externally peer reviewed.

Data availability statement Data may be obtained from a third party and are not publicly available.

Open access This is an open access article distributed in accordance with the Creative Commons Attribution Non Commercial (CC BY-NC 4.0) license, which permits others to distribute, remix, adapt, build upon this work non-commercially, and license their derivative works on different terms, provided the original work is 
properly cited, appropriate credit is given, any changes made indicated, and the use is non-commercial. See: http://creativecommons.org/licenses/by-nc/4.0/.

ORCID iD

Magnus Helgesson http://orcid.org/0000-0002-7868-9712

\section{REFERENCES}

1 Försäkringskassan. (The Swedish Social Insurance Agency). Sjukskrivningar i olika yrken under 2000-talet [in Swedish] (Sickness absence in different occupations in the 2000s). Socialförsäkringsrapport 2012;14. (Social Insurance Report 2012:14).

2 Försäkringskassan. (The Swedish Social Insurance Agency). Analys av sjukfrånvarons variation - Väsentliga förklaringar av upp- och nedgång över tid [In Swedish](Analyzing the variation in the level of sickness absence - essential explanations to the ups and downs in sick leave). Socialförsäkringsrapport 2014;17. (Social Insurance Report 2014:17).

3 AFA. Psykiska diagnoser I kontaktyrken inom vård, skola och omsorg [In Swedish]. Stockholm: AFA Försäkring, 2015.

4 Försäkringskassan. (The Swedish Social Insurance Agency), Sjukfrånvaron på svensk arbetsmarknad [in Swedish] (Sickness absence in the Swedish labor market). Socialförsäkringsrapport 2018:2 (Social insurance report 2018:2), 2018.

5 Beemsterboer W, Stewart R, Groothoff J, et al. A literature review on sick leave determinants (1984-2004). Int J Occup Med Environ Health 2009;22:169-79.

6 Bronkhorst B, Tummers L, Steijn B, et al. Organizational climate and employee mental health outcomes: a systematic review of studies in health care organizations. Health Care Manage Rev 2015;40:254-71.

7 Janssens $\mathrm{H}$, Braeckman L, De Clercq B, et al. The relation between indicators of low employment quality and attendance behavior in countries of the European Union. J Public Health 2017;39:e127-33.

8 Laaksonen M, Pitkäniemi J, Rahkonen O, et al. Work arrangements, physical working conditions, and psychosocial working conditions as risk factors for sickness absence: Bayesian analysis of prospective data. Ann Epidemiol 2010;20:332-8.

9 Brown J, Mackay D, Demou E, et al. The easy (early access to support for you) sickness absence service: a four-year evaluation of the impact on absenteeism. Scand J Work Environ Health 2015;41:204-15.

10 Demou E, Smith S, Bhaskar A, et al. Evaluating sickness absence duration by musculoskeletal and mental health issues: a retrospective cohort study of Scottish healthcare workers. BMJ Open 2018;8:e018085.

11 Foss L, Gravseth HM, Kristensen P, et al. The impact of workplace risk factors on long-term musculoskeletal sickness absence: a registry-based 5-year follow-up from the Oslo health study. $J$ Occup Environ Med 2011;53:1478-82.

12 Eriksen W, Bruusgaard D, Knardahl S. Work factors as predictors of sickness absence: a three month prospective study of nurses' aides. Occup Environ Med 2003;60:271-8.

13 Andersen LL, Clausen T, Mortensen OS, et al. A prospective cohort study on musculoskeletal risk factors for long-term sickness absence among healthcare workers in eldercare. Int Arch Occup Environ Health 2012;85:615-22.

14 Andersen LL, Clausen T, Persson R, et al. Dose-response relation between perceived physical exertion during healthcare work and risk of long-term sickness absence. Scand J Work Environ Health 2012;38:582-9.

15 Roelen CAM, Stapelfeldt CM, Heymans MW, et al. Cross-National validation of prognostic models predicting sickness absence and the added value of work environment variables. J Occup Rehabil 2015;25:279-87.

16 van der Meer EWC, Boot CRL, van der Gulden JWJ, et al. Hand eczema among healthcare professionals in the Netherlands: prevalence, absenteeism, and presenteeism. Contact Dermatitis 2013;69:164-71.

17 Swedish Research Council for health, working life and welfare (FORTE). Psykisk ohälsa, arbetsliv och sjukfråvaro - en kunskapsöversikt [In Swedish] [Mental illness, work life and sickness absence - A review]. Vingård $\mathrm{E}$, ed, 2015.

18 Christensen KB, Nielsen ML, Rugulies R, et al. Workplace levels of psychosocial factors as prospective predictors of registered sickness absence. J Occup Environ Med 2005;47:933-40.

19 Janssens $H$, Clays E, De Clercq $B$, et al. The relation between psychosocial risk factors and cause-specific long-term sickness absence. Eur J Public Health 2014;24:428-33.

20 Niedhammer I, Chastang J-F, Sultan-Taïeb H, et al. Psychosocial work factors and sickness absence in 31 countries in Europe. Eur J Public Health 2013;23:622-9.

21 Nielsen * ML, Rugulies R, Christensen KB, et al. Impact of the psychosocial work environment on registered absence from work: a two-year longitudinal study using the IPAW cohort. Work Stress 2004;18:323-35.

22 Nieuwenhuijsen K, Bruinvels D, Frings-Dresen M. Psychosocial work environment and stress-related disorders, a systematic review. Occup Med 2010;60:277-86.

23 Clausen T, Nielsen K, Carneiro IG, et al. Job demands, job resources and long-term sickness absence in the Danish eldercare services: a prospective analysis of register-based outcomes. J Adv Nurs 2012;68:127-36.

24 Kivimaki M, Vahtera J, Kawachi I, et al. Psychosocial work environment as a risk factor for absence with a psychiatric diagnosis: an instrumental-variables analysis. Am J Epidemiol 2010;172:167-72.

25 McVicar A. Workplace stress in nursing: a literature review. J Adv Nurs 2003;44:633-42.

26 Peterson U, Demerouti E, Bergström G, et al. Work characteristics and sickness absence in burnout and nonburnout groups: a study of Swedish health care workers. Int J Stress Manag 2008;15:153-72.

27 Piko BF. Burnout, role conflict, job satisfaction and psychosocial health among Hungarian health care staff: a questionnaire survey. Int J Nurs Stud 2006;43:311-8.

28 Rauhala A, Kivimäki M, Fagerström L, et al. What degree of work overload is likely to cause increased sickness absenteeism among nurses? Evidence from the RAFAELA patient classification system. $J$ Adv Nurs 2007:57:286-95.

29 Rugulies R, Christensen KB, Borritz M, et al. The contribution of the psychosocial work environment to sickness absence in human service workers: results of a 3-year follow-up study. Work Stress 2007;21:293-311.

30 Swedish Work Environment Authority (SWEA). Arbetsmiljön 2015 [The Work Environment 2015] [In Swedish]. Arbetsmiljöstatistik Rapport 2016:2. Stockholm, Sweden: Arbetsmiljöverket [Swedish Work Environment Authority], 2016.

31 Leineweber C, Marklund S, Aronsson G, et al. Work-Related psychosocial risk factors and risk of disability pension among employees in health and personal care: a prospective cohort study. Int J Nurs Stud 2019;93:12-20.

32 Hall C, Hartman L. Moral hazard among the sick and unemployed: evidence from a Swedish social insurance reform. Empir Econ 2010;39:27-50.

33 Henrekson M, Persson M. The effects on sick leave of changes in the sickness insurance system. J Labor Econ 2004;22:87-113.

34 Lidwall U, Marklund S. What is healthy work for women and men? - A case-control study of gender- and sector-specific effects of psycho-social working conditions on long-term sickness absence. Work 2006;27:153-63.

35 Lidwall U, Marklund S. Trends in long-term sickness absence in Sweden 1992-2008: the role of economic conditions, legislation, demography, work environment and alcohol consumption. Int J Soc Welf 2011;20:167-79.

36 Krane L, Johnsen R, Fleten N, et al. Sickness absence patterns and trends in the health care sector: 5-year monitoring of female municipal employees in the health and care sectors in Norway and Denmark. Hum Resour Health 2014;12:37.

37 Dellve L, Karlberg C, Allebeck P, et al. Macro-organizational factors, the incidence of work disability, and work ability among the total workforce of home care workers in Sweden. Scand J Public Health 2006;34:17-25. 